\title{
JOGO COMO PATRIMÔNIO CULTURAL: MUSEUS DE BRINQUEDOS NO BRASIL
}

\author{
GAMES AS CULTURAL HERITAGE: TOYS MUSEUMS IN BRAZIL
}

JUEGO COMO PATRIMONIO CULTURAL: MUSEOS DE JUGUETES EN BRASIL

\author{
Elizara Carolina Marin*, Mariani Guedes Santiago*
}

\section{Palavras chave: Jogos e brinquedos. Características culturais. \\ Museu. \\ Educação Física.}

Resumo: Esta pesquisa tem como objetivo situar os museus de brinquedos no Brasil e, especificamente, compreender a história da constituição, acervo e relação educativa do Museu do Brinquedo Popular, localizado no Instituto Federal do Rio Grande do Norte - Cidade Alta, Natal/RN. Por meio de análise documental, de entrevistas e observações, identificamos ser um museu de brinquedos constituído por artefatos elaborados pelos próprios jogadores. Destaca-se a importância da pesquisa na Educação Física, identificando, registrando e reunindo no espaço museal parte do patrimônio lúdico desenvolvido pelas comunidades. Muito do processo e significados destes brinquedos esmaece quando são transportados para o museu, mas, ali, ganham a possibilidade educativa de congregar a diversidade que estava dispersa, construir novas relações sociais, evocar a memória, provocar o desejo de brincar e reconhecer o jogo como patrimônio cultural material e imaterial.

\section{Keywords:} Games and toys.

Cultural

characteristics.

Museum.

Physical Education.

Abstract: This study looks into toys museums in Brazil to understand the history of establishment, the collections and the educational relationship of the Museu do Brinquedo Popular, located at the Instituto Federal do Rio Grande do Norte, in Cidade Alta, Natal, RN. Using documentary analysis, interviews and observations, the study found that it is a toy museum of artifacts made by the very people who played with them. Its constitution highlights the importance of research in Physical Education, identifying, recording and gathering part of the playful heritage developed by the communities in the space of the museum. Much of the process and meanings of these toys fade when they are transferred to the museum but they gain the educational possibility of gathering the diversity that was dispersed, building new social relations, evoking memory, provoking the desire to play, and recognizing game as material and immaterial heritage.

Palabras clave: Juegos y juguetes. Características culturales.

Museo. Educación Física.
Resumen: Esta investigación tiene el objetivo de situar los museos de juguetes en Brasil y, específicamente, comprender la historia de la constitución, el acervo y la relación educativa del Museo del Juguete Popular, que se encuentra en el Instituto Federal de Rio Grande do Norte/Cidade Alta/Natal-RN. Realizada a través de análisis documental, de entrevistas y observaciones, identificamos ser un museo de juguetes constituido por artefactos elaborados por los propios jugadores. Se destaca la importancia de la investigación en la Educación Física, identificando, registrando y reuniendo en el espacio del museo parte del patrimonio lúdico desarrollado por las comunidades. Mucho del proceso y significados de estos juguetes se desvanecen al ser transportados para el museo, pero, allí, ganan la posibilidad educativa de congregar la diversidad que estaba dispersa, de construir nuevas relaciones sociales, evocar la memoria, provocar el deseo de jugar y reconocer el juego como patrimonio cultural material e inmaterial.
*Universidade Federal de Santa Maria (UFSM). Santa Maria, RS, Brasil. E-mail: elizaracarol@yahoo.com.br marianisantiago@gmail.com

Recebido em: 21-10-2018 Aprovado em: 29-04-2019 Publicado em: 26-08-2019

DOI https://doi.org/10.22456/1982-8918.87591 (c) (i) () Licence 


\section{JOGO COMO PATRIMÔNIO MATERIAL E IMATERIAL}

No contexto mundial observa-se um movimento recente de pensar o jogo e/ou 0 brinquedo, entre outras manifestações culturais gestadas pelo povo, como patrimônio material e imaterial da humanidade e como artefato museológico.

A noção de patrimônio advém etimologicamente da concepção de "herança paterna". Nas línguas românicas, explicam Funari e Carvalho (2005, p.34), o termo patrimônio deriva do latim patrimonium e faz alusão à "propriedade herdada do pai ou dos antepassados" ou "aos monumentos herdados das gerações anteriores". Nas últimas décadas do século XX a compreensão de patrimônio se alargou. Partindo da definição de sítios arqueológicos, obras de arte, monumentos, conjuntos arquitetônicos e objetos de um determinado segmento social - em geral, representantes do poder econômico e político, como destaca Arantes (2004) -, 0 entendimento de patrimônio passa a incorporar as representações, práticas e expressões que caracterizam a cultura de cada povo, transmitida através de festas, rituais, danças, ritmos e modos de fazer enraizados no cotidiano das comunidades.

Essa expansão resultou, como assinalam Pelegrini e Funari (2013), majoritariamente, de pressões externas à Europa, que pressionam a Organização das Nações Unidas para a Educação, a Ciência e a Cultura (UNESCO) a pensar no patrimônio imaterial. Foram países da América Latina, a exemplo da Bolívia, Peru e México, que, entre os anos de 1970 e 1980, protagonizaram mudanças no cenário, solicitando a defesa do patrimônio cultural tradicional das comunidades via convenções nacionais e sistematização de Cartas e Declaração. Também, no Brasil, as sucessivas pressões resultantes da expansão de movimentos sociais abriram caminho para a revisão de diferentes temas, dentre eles, o patrimônio, o que resultou na ampliação da legislação, ao serem incluídos bens tangíveis e intangíveis na constituição de 1988. Com isso, fundou-se, em 2000, o Programa Nacional para a Salvaguarda do Patrimônio Cultural Imaterial, por meio do Decreto Federal n. 3551, elaborado pelo Instituto do Patrimônio Histórico e Artístico Nacional (Iphan), situado no Ministério da Cultura.

Desse modo, teve início um processo de proteção de patrimônio imaterial, orientado por uma percepção antropológica de cultura, e que antecedeu a aprovação da Convenção para a Salvaguarda do Patrimônio Imaterial, ocorrida em 2003, pela UNESCO (PELEGRINI; FUNARI, 2013). Em entrevista concedida a Labate e Goldstein (2009), Antônio Arantes elucida que, na prática, diferenciaram-se os instrumentos de proteção a serem utilizados para a salvaguarda do patrimônio imaterial. $O$ termo tombamento, que determina a manutenção ou conservação física de um bem patrimonial, é utilizado em relação ao patrimônio material. De outro modo, o termo salvaguarda é utilizado para casos de patrimônio de natureza imaterial, que é vivo e dinâmico.

No âmbito museológico, aponta Padiglione (2010; 2013), esta acepção introduz a relação entre museu e vida, e abre para a possibilidade de expor as atividades das pessoas comuns e suas vidas cotidianas, como, em nosso caso, os jogos e/ou brinquedos. 0 que vai para além, portanto, da acepção histórica de museus, centrada na cultura material e hegemônica, que conserva, expõe, comunica, para fins de preservação e conhecimento, conjuntos e coleções de valor histórico, artístico, científico e técnico.

É importante ressaltar que o reconhecimento dos jogos, de seus materiais e instrumentos como patrimônio cultural no continente americano e no mundo é recente. Porém, ainda mais 
recente é o reconhecimento de jogos como patrimônio cultural imaterial, datado do século XXI. Em meio aos jogos já reconhecidos, presentes na lista da UNESCO, podemos destacar o Chovkan (jogo equestre) da República do Azerbaijão, inscrito em 2013; o rito e jogos de tiro de corda realizados por cultivadores de arroz em países da Ásia (Camboja, Filipinas, Vietnam e República da Coreia), inscrito em 2015; a roda de capoeira, do Brasil, inscrita pela UNESCO em 2014 (MARIN, 2017).

Historicamente, os jogos e/ou brinquedos estiveram presentes nos museus como peças arqueológicas, etnográficas, artísticas, tal como no Museu da Acrópole, em Atenas, na Grécia (que expõe p.ex. bolas, dados e animais em miniatura), no Museu Nacional Romano, em Roma, na Itália (p.ex. pequenos bonecos em cobre). Uma tendência estendida inclusive ao Brasil, como descreve Guedes (2002; 2003; 2004)), por meio de sua ação e pesquisa no Museu Histórico Nacional ${ }^{1}$ (MHN), no Rio de Janeiro, o qual apresentava como um dos primeiros objetos coletados (em 1922) um tabuleiro de xadrez do século XIX, um barco (em miniatura) em marfim, movido a corda, peças pertencentes ao Imperador D. Pedro I. O início efetivo de um acervo de brinquedos neste museu ocorre em 1986 e se intensifica a partir de 1997, constituindo uma seção de brinquedos. Como relata Guedes (2003, p. 139), o Museu Histórico Nacional "estava essencialmente voltado para recolher e preservar os objetos e testemunhos da história, dos grandes feitos da nação, das personalidades do país". No horizonte deste projeto político e social não havia espaço para o brinquedo e o brincar em sua singularidade, menos ainda em sua diversidade.

Afinal, de que jogos e/ou brinquedos estamos falando? Especificamente do tradicional, caracterizado por Cascudo (1972) como "brinquedo popular", ou seja, como sendo

[...] sinônimo de jogos, rondas, divertimentos tradicionais infantis, cantados, declamados, ritmados ou não, de movimento, etc. Brinquedo é ainda o objeto material para brincar, carro, arco, boneca, soldado. Também dirá a própria ação de brincar. Brinquedo de dona de casa, de cobra-cega, de galinha-gorda, de chicote queimado (CASCUDO, 1972, p.170).

Diferenciar entre brinquedo, brincadeiras, jogos e até mesmo folguedo cria dificuldades, ou ainda inviabiliza compreendê-los. Isso porque, na cultura popular, um folguedo como o Bumba meu boi, que mistura teatro, dança, música e circo, é denominado brincadeira pelos participantes. Daí porque os participantes dessas brincadeiras se autodenominam "brincantes", aqueles que brincam e fazem brincar. Termo também muito utilizado pelo multiartista Antônio Nóbrega, como destacam Coelho e Falcão (1995, p.62), para designar o bufão, palhaço, arlequim, brincador, esse tipo popular que povoa de alegria as ruas e praças do Brasil, que encenam papéis lúdicos, "cujo espetáculo em que participa é o Brinquedo". A articulação entre jogo, brinquedo e brincante também vem sendo adotada na psicologia da arte (MOREIRA, 2015), no lazer (SAURA, 2014), na Educação (SOUZA, 2001) na Educação Física (MARIN; RIBAS, 2013; SAURA, 2014; SANTIAGO, 2017) e como proposição pedagógica (GOMES-DA-SILVA, 2016).

Partindo desses pressupostos buscamos identificar os museus de jogos e/ou brinquedos catalogados e cadastrados no Guia dos Museus Brasileiros/GMB (INSTITUTO BRASILEIRO DE MUSEUS, 2011)2, trabalho desenvolvido pelo Instituto Brasileiro de Museus (Ibram), e

\footnotetext{
1 Fundado em 1922, o Museu Histórico Nacional tornou-se o mais importante museu de história do país, por reunir um acervo com cerca de 258 mil itens, entre objetos, documentos e livros, e por ser uma instituição de produção e difusão de conhecimento.

20 Guia dos Museus Brasileiros apresenta 3.118 museus, incluindo 23 museus virtuais, mapeados pelo lbram em território nacional até o ano de 2011. Organizado por região do país, traz dados sobre o ano de criação, situação atual, endereço, horário de funcionamento, tipologia de acervo, acessibilidade, infraestrutura e natureza administrativa.
} 
compreender a especificidade do Museu do Brinquedo Popular, localizado no Rio Grande do Norte, referente à história de sua constituição, ao acervo, sua disposição espacial e proposição educativa. A escolha deste museu se deu por ser bastante representativo em relação ao tema abordado, além de apresentar muitas semelhanças com os demais, relativas a funcionamento e dificuldades. Mas, especialmente, por este museu ter sido resultado de larga pesquisa de campo, coordenada por pesquisadores da área da Educação Física e lazer.

Realizamos análise documental, via pressupostos de Cellard (2012), levando em conta as seguintes fontes: Guia dos Museus Brasileiros; Projeto do Museu registrado no IFRN (OLIVEIRA, 2016b3); Ata da Reunião com os Coordenadores dos Museus de Jogos, realizada no dia 23 de outubro de 2015, como parte da Programação do III Encontro Pan-americano de Jogos e Esportes Autóctones e Tradicionais - Palmas/TO (ENCONTRO PAN-AMERICANO DE JOGOS E ESPORTES AUTÓCTONES E TRADICIONAIS, 2015). Também fez parte das opções metodológicas pesquisa de campo realizada por meio de entrevista (com o coordenador do Museu) e observações, ancoradas em Minayo (2009), realizadas nos períodos de 20 a 24 de junho de 2016, 12 de agosto de 2016 e 26 de fevereiro de 2018.

\section{MUSEU DE BRINQUEDOS NO TERRITÓRIO BRASILEIRO}

O âmbito da constituição/formalização de museus específicos de jogos e/ou brinquedos tem início na Europa, por volta dos anos 1980, a exemplo de SpeelgoedMuseum, na Bélgica, em 1982 e Musée Suisse du Jeu, na Suíça, em 1987. Já no Brasil, esse movimento ocorre, majoritariamente, a partir dos anos de 1990.

Com base no mapeamento realizado pelo Ibram, identificamos oito museus específicos de brinquedos e/ou jogos no território nacional, o que não significa a totalidade, ilustrados na Figura 1.

Figura 1- Mapa dos Museus de Brinquedos no Brasil

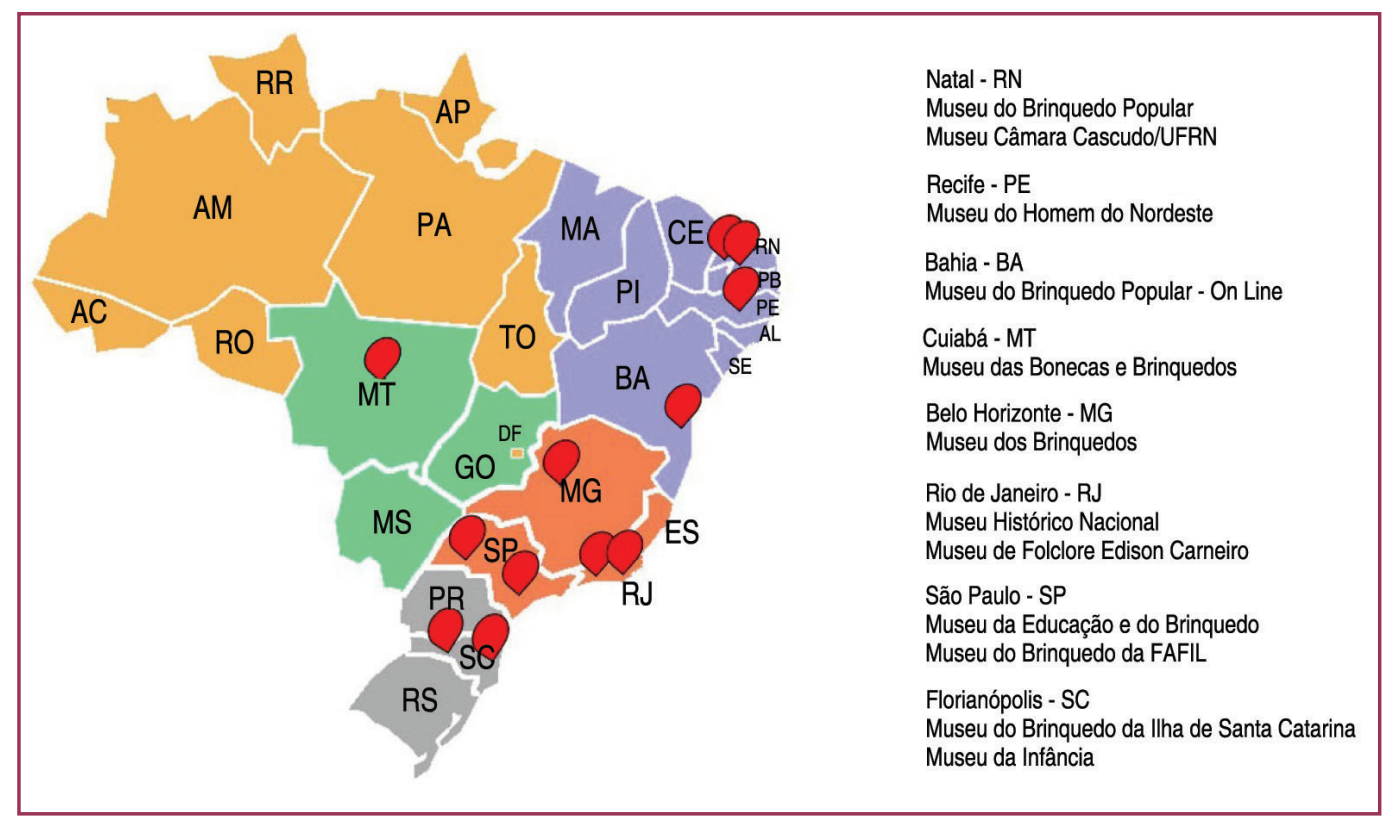

Fonte: Arquivo da autoria

3 OLIVEIRA, Marcus Vinícius Farias. Museu do Brinquedo Popular. Instituto Federal de Educação, Ciência e Tecnologia do Rio Grande do Norte. Pró Reitoria de Extensão Projeto de Extensão - Fluxo contínuo. Edital de fluxo contínuo № 01/2016 PROEX/IFRN. 2016b. Trabalho não publicado. 
Identificamos que a iniciativa de constituição destes museus foi individual ou de um pequeno grupo. Seis deles estão ligados a instituições de ensino superior, derivados da iniciativa de pesquisadores que objetivaram a formação de professores via experiência lúdica, tal como assinalam Camilo (2010) e Rogério (2013), embora a visitação (os usos) demonstre transbordar os fins acadêmicos.

Conforme o mapeamento dos museus (Figura 1), passamos à apresentação de cada um. Iniciamos com a Região Sul, onde estão localizados dois museus. Um deles, o Museu do Brinquedo da llha de Santa Catarina, localizado na Universidade Federal de Santa Catarina/ UFSC, de natureza pública, federal, fundado em 1999. Abriga acervo do tipo histórico, contando com 144 peças catalogadas. O outro, o Museu da Infância, localizado na Universidade do Extremo Sul Catarinense/Unesc, foi criado em 2005, e apresenta um acervo que perpassa áreas da Antropologia e Etnografia, Artes Visuais, Imagem e Som. Como forma de ampliar as possibilidades de conhecer este museu, em 2006 foi lançado o Museu Virtual da Infância, com um banco de dados no qual estão cadastrados mais de 700 itens relativos à infância.

$\mathrm{Na}$ Região Sudeste encontram-se três museus, dois em São Paulo ligados a instituições de ensino superior, e um em Minas Gerais, sendo respectivamente o Museu da Educação e do Brinquedo (MEB), localizado na Universidade de São Paulo/USP, de natureza pública - estadual, foi criado em 1985 (atualmente desativado). Conta com 555 peças (bonecas, carrinhos, acessórios para cozinha, jogos, casinhas de bonecas, brinquedos musicais e eletrônicos), 128 brinquedos artesanais, 98 livros infantis e didáticos, 200 registros fotográficos das primeiras pré-escolas paulistas e três mil jogos do Brasil e de outros países. E o Museu do Brinquedo da FAFIL, localizado na Faculdade de Filosofia, Ciências e Letras "Carlos Queiroz" (Santa Cruz do Rio Pardo), criado em 2008 (atualmente desativado), de natureza privada, apresenta acervo do tipo Artes Visuais. Por fim, em Minas Gerais há o Museu dos Brinquedos, de natureza privada - fundação, ligado ao Instituto Cultural Luiza Meyer de Azevedo, criado em 2003, com acervo de aproximadamente 5 mil peças, sendo a tipologia do acervo História, Imagem e Som.

Na Região Centro-Oeste, em Cuiabá/Mato Grosso, foi inaugurado, em 1999, o Museu das Bonecas e dos Brinquedos. De natureza privada, originou-se da ação entusiasmada de colecionadora que assume o trabalho de constituir e recuperar o acervo, de organizar o espaço e mediar as visitações. Compõem o acervo em torno de 6 mil itens composto por bonecas(os) com seus assessórios e mobiliário de diferentes culturas e países.

E, na Região Nordeste, encontra-se o Museu da Infância e do Brinquedo, antes ligado à Universidade Federal do Ceará/Fortaleza, criado em 2012, atualmente denominado Museu do Brinquedo de Fortaleza, conta com um acervo de aproximadamente 2.500 brinquedos; e o Museu do Brinquedo Popular, ligado ao Instituto Federal do Rio Grande do Norte - Campus Cidade Alta, Natal/RN, de natureza público-federal, criado em 2009, o qual passamos a destacar a seguir.

\section{MUSEU DO BRINQUEDO POPULAR - IFRN}

A extensa pesquisa de campo realizada no período de 2006 a 2008 pelo Núcleo de Estudos Culturais da Ludicidade Infantil (NECLI-IFRN), que objetivou conhecer "o mundo que compõe a ampla produção sócio-histórica e cultural da ludicidade infantil norte-rio-grandense" 
(OLIVEIRA et al., 2010, p.15), resultou no livro Brinquedos e brincadeiras populares: identidade e memória (2010), e no acervo de mais de 300 brinquedos, os quais constituem um contributo para o inventário e preservação de todo um patrimônio cultural criado, produzido e reproduzido por crianças e adultos norte-rio-grandenses.

Esta quantidade e variedade de brinquedos, associada à experiência dos pesquisadores com Educação Física e educação infantil, resultou, inicialmente, em exposições destes brinquedos pela cidade - no Campus Central do Instituto Federal do Rio Grande do Norte (IFRN) e na Pinacoteca da cidade - e posterior acervo do Museu do Brinquedo Popular, instalado no novo prédio do IFRN, no bairro Cidade Alta. Segundo Oliveira (2016a, p.125), é um prédio com valor histórico para a cidade, restaurado com a finalidade de "funcionar como centro cultural e de formação profissional, com cursos voltados para a cultura".

Entre os objetivos da criação do Museu destaca-se, nas palavras de Oliveira (2016b) preservar e difundir a cultura lúdica da criança potiguar, "construída na argamassa de múltiplas culturas, entre as quais pode-se mencionar a influência africana, indígena e portuguesa entre outras [...]".

A constituição do Museu se concretizou pelo esforço e dedicação de um pequeno grupo de pessoas, não sem conflitos devido a interesses diversos referentes a estrutura física, orçamentária e recursos humanos. Do mesmo modo, sua continuidade também contou com a colaboração do grupo, na medida em que diferentes funções são assumidas para a sua manutenção, a exemplo de restauração do acervo, agenda das visitas, formação dos guias, entre outras.

Comungam dificuldades expressas pelos demais museus de brinquedos do país, conforme Ata (ENCONTRO PAN-AMERICANO DE JOGOS E ESPORTES AUTÓCTONES E TRADICIONAIS, 2015), quer seja no âmbito da manutenção, qualificação e divulgação dos museus por falta de: verbas; compreensão social acerca da importância da prática museal; políticas públicas municipais, estaduais e federais; entendimento do museu como espaço educativo e investigativo; articulações com o lbram; qualificação dos profissionais que atuam no museu; constituição de espaço físico para reserva técnica; planejamento com relação a fomento, a vínculos com as mídias e métodos avaliativos das ações realizadas.

O Museu do Brinquedo Popular abre suas portas diariamente com a mediação e parceria acadêmica dos estudantes de diferentes cursos do IFRN - Cidade Alta, em especial, do curso Técnico Subsequente em Guia de Turismo, que atuam na secretaria e nas visitas guiadas de grupos escolares da cidade e região. Os estudantes assumem função especial no museu tanto na organização do acervo quanto na ação educativa comprometida com a compreensão e valorização do brinquedo. A capacitação para assumirem tal função deriva das reuniões de estudos com o gestor do museu.

Além de projeção local, angariou projeção estadual e nacional. Muito provavelmente, por congregar uma coleção que toca a todas as idades, segmentos sociais e gêneros. Benjamin (1984, p.64), na síntese elaborada sobre uma exposição de brinquedos antigos em 1928, já ressaltava o intenso interesse das crianças e dos adultos - incluso como objeto de pesquisa que levava a pequena sala de exposição a jamais ficar vazia. A resposta, para o autor, é que

4 OLIVEIRA, Marcus Vinícius Farias. Museu do Brinquedo Popular. Instituto Federal de Educação, Ciência e Tecnologia do Rio Grande 
"brincar significa sempre libertação". Bárbara Spadaccini, curadora da coleção de brinquedos do Museu de Artes decorativas de Paris, em entrevista para Guedes (2003, p.141), também assinala a seção de brinquedos como a mais atraente no museu, por propiciar "empatia imediata; é o elo entre gerações". Os brinquedos têm a magia de transportar de um tempo para outro, evocar lembranças da infância, ou de rituais e imagens ancestrais que nos constituem. Afinal, os jogos e/ou brinquedos foram e são fundamentais nas experiências das gerações passadas e atuais, devido "às habilidades que estimularam, às emoções que produziram, aos encontros que geraram, aos sonhos que alimentaram e aos sorrisos que provocaram [...]", sintetiza Amado (2010, p.13).

O acervo do Museu do Brinquedo Popular é, portanto, majoritariamente produto da criatividade e imaginação de moradores de 48 municípios norte-rio-grandenses, espalhados entre a zona urbana e rural. Significa dizer que é constituído com artefatos feitos pelas mãos dos brincantes/jogadores, artefatos do próprio brincar.

Sobre o piso vermelho do Museu, em alturas acessíveis ao toque, nas paredes e no teto, distribuem-se os brinquedos nos três ambientes conectados por amplas passagens, como demonstra a Figura 2.

Figura 2- Planta do Museu do Brinquedo Popular -IFRN

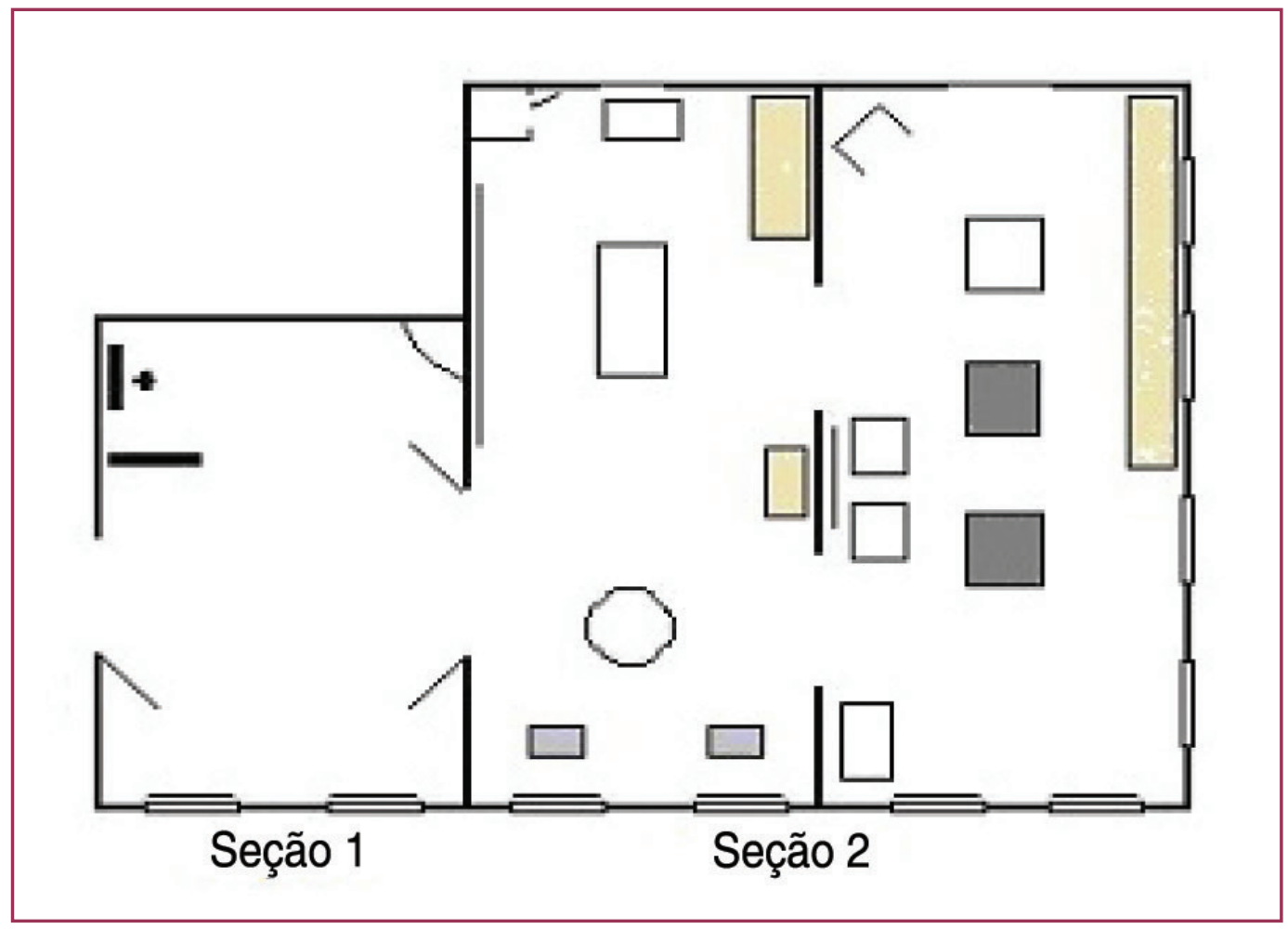

Fonte: Arquivo da autoria

Os brinquedos estão organizados no espaço segundo a lógica apresentada na pesquisa de campo que originou o Museu, ou seja, por diferentes seções ou temáticas: brinquedos de locomoção, rodas e transporte; brinquedos indígenas; brinquedos sonoros ou musicais; brinquedos e cenários de caça; bonecos e cenários de brincadeiras de cozinha com seus utensílios; representações de animais e cenário de vaquejada; brincadeiras em terra, areia e água. 
Reciprocamente, o espaço foi determinante nas escolhas dos brinquedos e sua localização. As grandes janelas do prédio histórico colaboram para a entrada da luz do sol e do vento dando brilho e movimento às peças, tais como os cata-ventos e as pipas.

Na entrada do Museu, seção 1, detalhes preenchem o olhar de imediato. Do lado direito, um trilho de trem chama a atenção pelo seu tamanho e conduz a cenários de ação, onde a brincadeira não receia o perigo (Figura 3). Neste mesmo espaço, também estão dispostos brinquedos de locomoção: roda e trava, patinete de ferro, pernas de pau, carrinhos de rolimã de tamanhos diversos, carro de cocão (assemelha-se ao carrinho de rolimã, porém em maiores proporções, construído com cocão, nome popular de uma espécie de palmeira), carrinhos de empurrar ou puxar de diversas cores e modelos. No canto da sala, há uma estante aberta com brinquedos artesanais, sempre com o mote de movimento. $\mathrm{O}$ olhar dirige-se para cima e encontra pipas e miniparaquedas no teto, sobrevoando a sala. Piso, parede e teto expõem o brincar livre, a exploração de movimentos em lugares diversos e brinquedos construídos com diferentes materiais - madeira, papel, ferro, pneu...

Figura 3 - Entrada do Museu do Brinquedo Popular - IFRN.

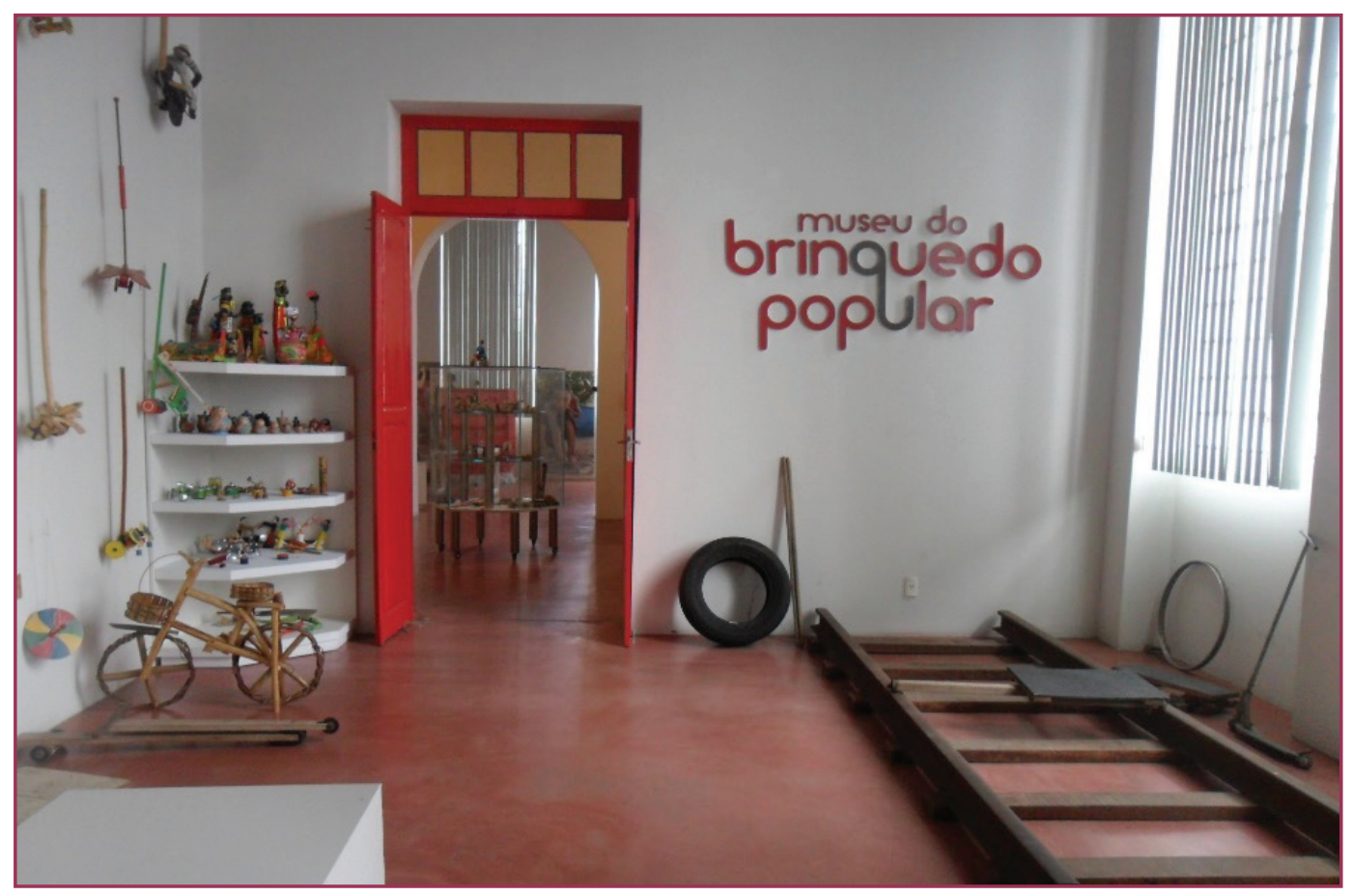

Fonte: Arquivo da autoria

Na seção 2, há dois ambientes interconectados por passagens que permitem uma visão geral do que se descortina no museu, que não se basta, pois o olhar e o desejo, impelem aos detalhes. Na primeira parte, uma estante hexagonal, logo na entrada, a única fechada e de vidro, sinaliza que também de elementos da natureza e sazonais - a casca, a folha, a semente, penas de aves - são construídos brinquedos (piões, petecas, ronrom...) que, por sua delicadeza e fragilidade, muitas vezes não resistem, no dizer de Amado (2010, p.10) "aos tratos e ao tempo", portanto, segue o autor, são "impróprios para a acumulação, insusceptíveis de virarem propriedade", pois a riqueza e o valor estão, em especial, no seu uso. A entrada desta seção assinala a forte presença indígena no Rio Grande do Norte, mais especificamente da Etnia Potiguar. 
Ainda no primeiro ambiente da seção 2, é possível notar a presença de um cenário denominado Parque Vaquejada, com uma variedade de cavalos de madeira de talo de carnaúba. À esquerda, brinquedos de transporte, carrinhos e caminhões, de madeira e de lata, de tamanhos variados, estacionados na extensão em frente à parede e dispostos também em prateleiras. No canto esquerdo, ao lado, fica a sala do jogo das sombras e, em frente a esta, há brinquedos de caça, espingardas e armadilhas para pequenos animais e aves. Um parque de diversões em lata ocupa o centro do espaço, com duas rodas-gigantes, um carrossel e uma barca (Figura 4).

Figura 4 - Miniatura parque de diversões, carrinhos, ambiente jogo das sombras, pinturas.

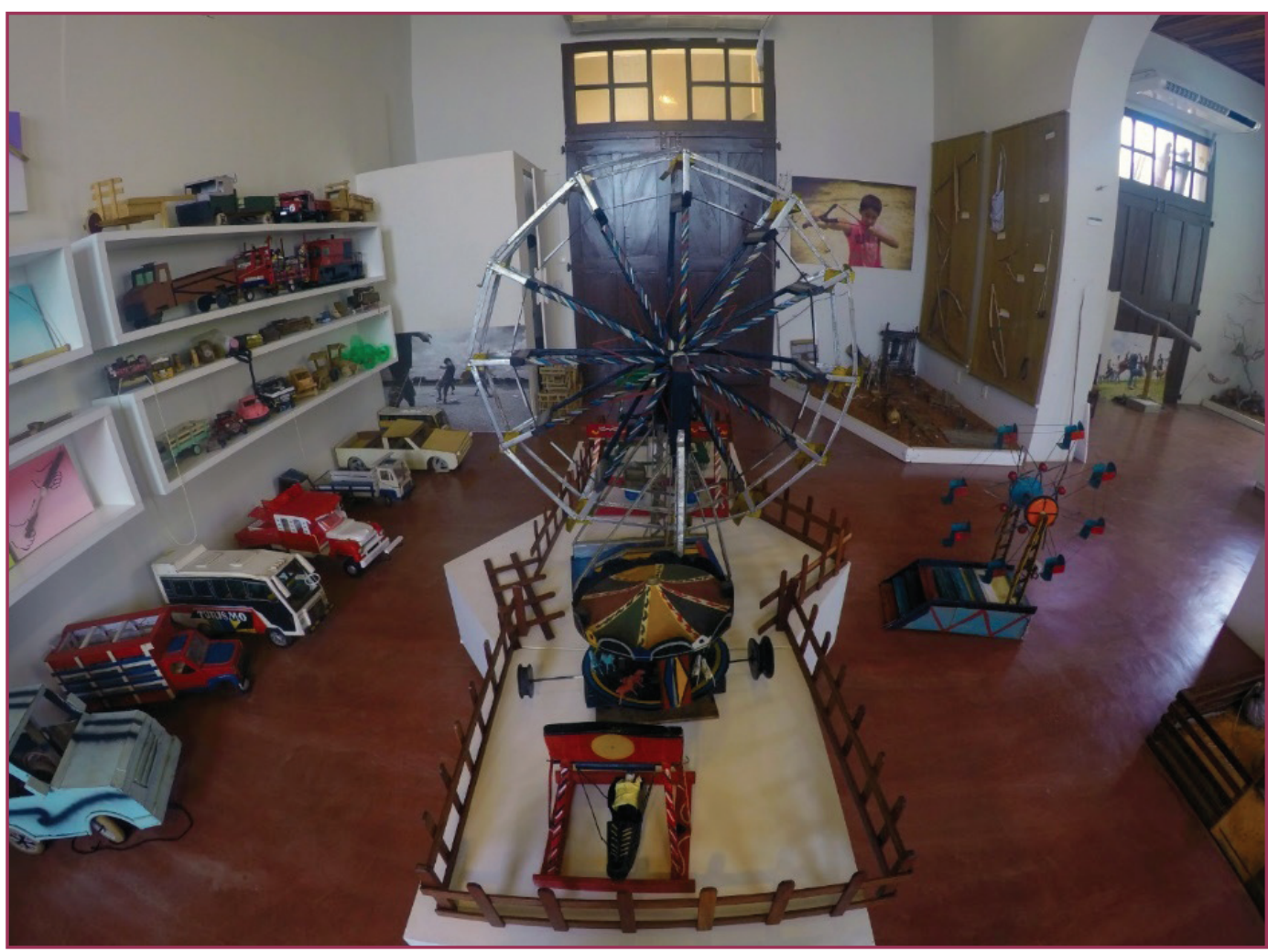

Fonte: Arquivo da autoria

No percurso de existência do museu foram também agregadas peças de doação, tais como quadros produzidos pelo autor português João Amado, que retratam o brincar lusitano. Brinquedos de madeira fixados em telas, com traços que representam o movimento do brincar. Obras brincantes, como ilustra a imagem anterior (à direita, acima dos caminhões), que permitem refletir sobre a herança e influência lusitana no Brasil, identificadas também pelos pesquisadores no universo lúdico.

Ao lado direito desse ambiente estão dispostas duas estantes (abertas) com brinquedos diversos, como corrupios, bolas, petecas, bilboquês, rói-rói, mané teimoso, bonecas de palha, alguns animais e brinquedos sonoros. $E$ duas mesas, uma com o jogo da onça - 0 tabuleiro feito em tecido, e as peças constituídas por castanhas e uma concha - e, a outra, com uma minissinuca.

Alguns televisores respondem à proposta interativa do Museu, visibilizando cenas de brincadeiras. No percurso dos espaços, também há imagens com crianças brincando, no 
formato de grandes painéis, permitindo a sensação de movimento dos jogos e brinquedos. Desse modo, mescla o brinquedo que está exposto com a imagem fotográfica de crianças brincando (Figura 5), permitindo ao visitante visualizar a brincadeira em ação, despertando a imaginação, a memória e o desejo da experiência.

Figura 5 - Caixa de areia e painel fotográfico

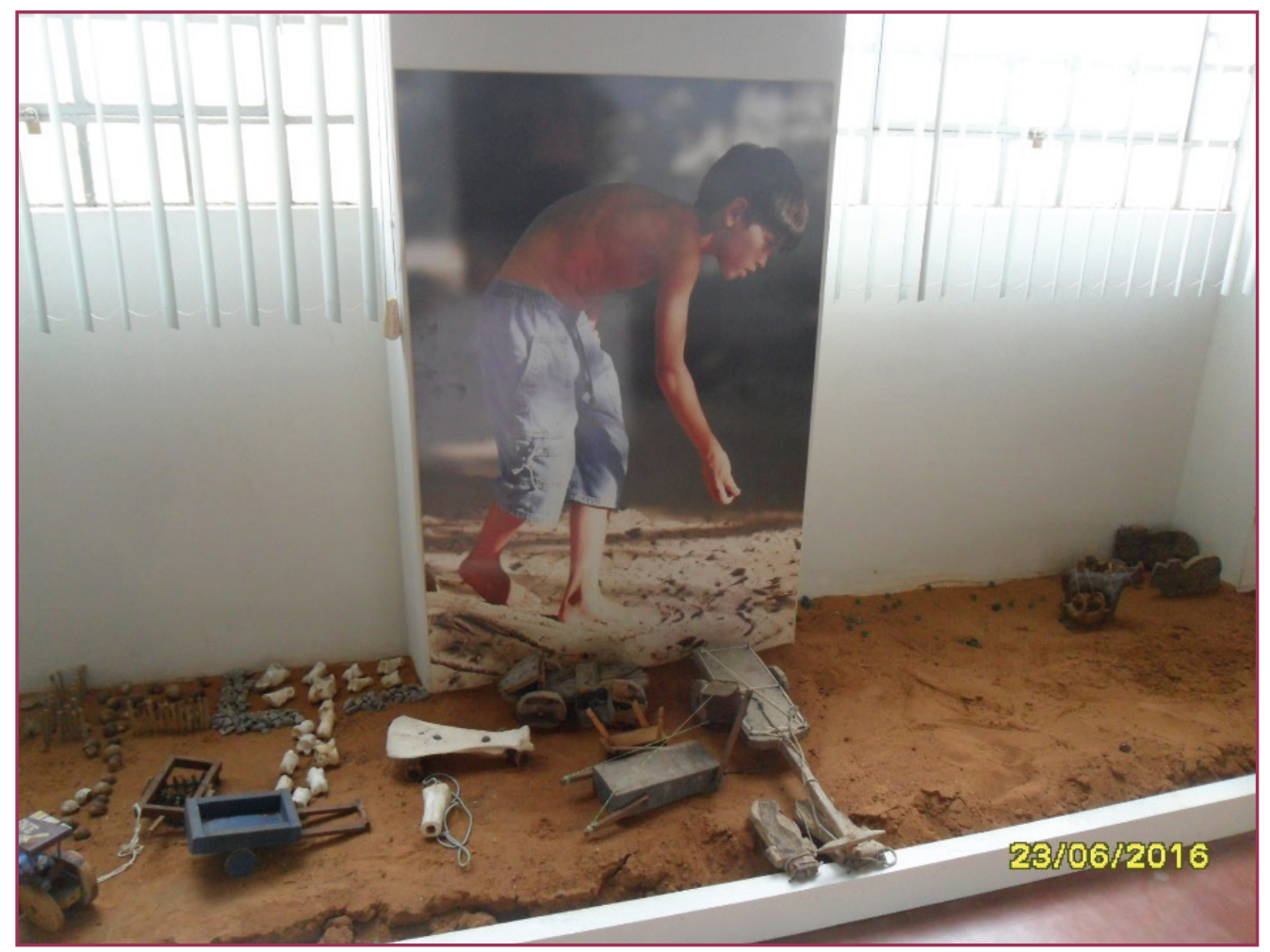

Fonte: Arquivo da autoria

No segundo ambiente da seção 2, ao fundo (Figura 5), abre-se o cenário dos brinquedos e brincadeiras com a terra e a areia, que se desenrolam nos quintais, ruas, terrenos baldios, praias, entre outros, das comunidades potiguares (como o jogo do peixe) e do mundo (como a bolita/bola de gude, carrinhos, carreta de boi e o curral de ossos).

Também na diversidade deste ambiente encontra-se a casinha de bonecas com acessórios construídos de pano, osso, sabugo de milho e móveis de madeira em miniatura, e que, com as portas abertas, é, em si, brincante e convidativa.

Chama atenção um biombo com um boneco de mamulengo, assinalando que 0 teatro, as danças, as cirandas e as parlendas fazem parte do universo lúdico. Também se destacam o cata-vento construído de lata em formato de avião, que, com o vento, move os passageiros; os brinquedos e brincadeiras em água doce e salgada, como os barcos feitos com madeira, isopor, chinelo de borracha, sacola plástica etc., bem como o esqui-bunda, objeto plano que permite deslizar nas dunas existentes nas praias do Rio Grande do Norte (Figura 6). 
Figura 6 - Mamulengo, cata-vento, barcos e dunas

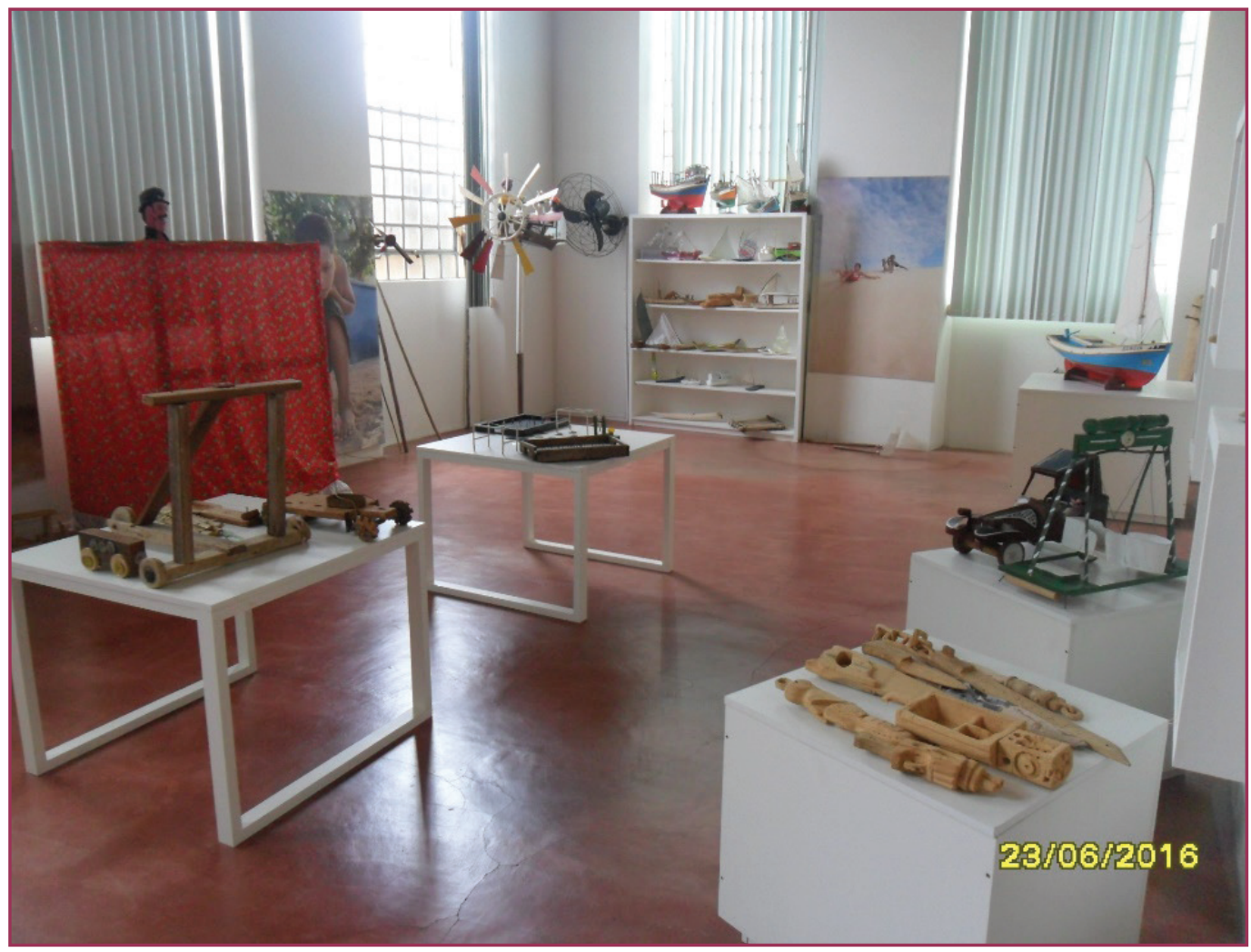

Fonte: Arquivo da autoria

O museu utiliza mobília discreta - mesas, cubos, caixas e estantes -, o que permite destaque aos brinquedos, dispostos em alturas que possibilitam o alcance dos olhos (em sua maioria também das mãos) de crianças e adultos de todos os tamanhos. Utiliza linguagens diversas - brinquedos, cenários, fotografias, obras de arte, mídias - a fim de produzir experiências também diversas, que vão da alegria e emoção de encontrar o conhecido à surpresa do desconhecido e imprevisto.

Percorrer o Museu do Brinquedo Popular sugere percorrer os passos dos pesquisadores e entrar no cenário dos brincantes pesquisados. Um museu que evidencia menos as informações institucionais e mais a produção dos diferentes grupos sociais do Rio Grande do Norte. Pode-se dizer, mais próximo do museu etnográfico e interpretativo, e distante dos museus tradicionais. Como explica Padiglione (2013, p. 2), o museu interpretativo "[...] não se baseia apenas na ideia estática de coleção. Valoriza uma noção processual de coleção, baseada numa interpretação etnográfica. A linguagem visual é mais valorizada do que a linguagem textual e isto dá mais liberdade para quem aprecia a exposição". E assim sendo, mais aproxima o visitante do que distancia.

Um museu com acervo específico de jogo e/ou brinquedo em sua diversidade étnica - construído pelos jogadores/brincantes e derivado de pesquisa -, ao evidenciá-los, abre-se como espaço educativo de mudança de sentido e de interesse, como declaração pública da importância do jogo e/ou brinquedo na vida, e como via para considerá-los como patrimônio material e imaterial. 


\section{CONSIDERAÇÕES FINAIS}

Em suma, nesse inventário do Museu do Brinquedo Popular, recheado de testemunhos, é possível encontrar, ao mesmo tempo, o caráter local, regional, nacional e universal, atravessando séculos, povos e culturas. Ademais, como assinala Cascudo (1983, p.32), para toda formação mítica e tradicional, "não é possível fixar a fórmula inicial", nem mesmo a fixar em um território específico, pois são "de movimento, de ambulação", nas matas, rios, sertões, caatingas, pampas, serras, chapadões, praias, roças, quintais, cidades, em viagens ininterruptas, imprevistas e irreversíveis. E nessa ambulação, os jogos revestem-se com outras cores, formatos, materiais, regras, cantigas e danças; revestem-se de materialidade e imaterialidade. 0 jogo e/ou brinquedo como patrimônio diz da relação afetiva que os jogadores/brincantes estabelecem com o território, com o espaço, com 0 outro.

O Museu apresenta a diversidade da experiência lúdica de todas as idades e de diferentes origens, e assinala a importância da pesquisa a fim de identificar, registrar e reunir, no espaço museal, parte do universo lúdico desenvolvido anonimamente, oralmente, difusamente pelas comunidades. A pesquisa e os pesquisadores facultaram ao público conhecer os jogos e/ou brinquedos; valorizaram e deram vozes aos sujeitos; potencializaram o pertencimento ao local; romperam as limitações das políticas municipais, estaduais, federais; e se entrelaçaram com a formação dos discentes do IFRN e da Educação Básica. Uniram a vontade de um grupo e deram existência a uma ação pública no âmbito do patrimônio lúdico.

Certamente, muito do processo e da alma dos jogos e/ou brinquedos esmaecem sua singularidade ao serem transportados para o museu, mas ali - dependendo da proposta, do espaço, do mobiliário, do pesquisador, do museólogo, entre outros - ganham a possibilidade de congregar a diversidade que estava dispersa, construir novas relações, encantar, emocionar, ensinar, evocar a memória, provocar o desejo de brincar e, substancialmente, reconhecer o jogo e o brinquedo como patrimônio material e imaterial.

\section{REFERÊNCIAS}

AMADO, João. Prefácio. In: OLIVEIRA, Marcus Vinícius Farias, et al. Brinquedos e brincadeiras populares: identidade e memória. Natal: IFRN Editora, 2010. p. 10-14.

ARANTES, Antônio A. O patrimônio imaterial e a sustentabilidade de sua salvaguarda. Revista Resgate, v.12, n.1, p.11-18, 2004. Disponível em: https://periodicos.sbu.unicamp.br/ojs/index.php/ resgate/article/view/8645608/12908 Acesso em: 10 out. 2018.

BENJAMIN, Walter. A criança, o brinquedo e a educação. São Paulo: Summus, 1984.

CAMILO, Zildete Torres Peres. Museu do Brinquedo da FAFIL: Um espaço cultural integrando o lúdico no ensino e aprendizagem da Arte para a formação de educadores. 2010. $234 \mathrm{f}$.

Dissertação (Mestrado) - Escola de Comunicações e Artes, Universidade de São Paulo, São Paulo, 2010. 
CASCUDO, Luís da Câmara. Dicionário do Folclore Brasileiro. 3. ed. Rio de Janeiro: Instituto Nacional do Livro. Ministério da Educação e Cultura, 1972. (Coleção Dicionários Especializados, 3)

CASCUDO, Luís da Câmara. Geografia dos mitos brasileiros. São Paulo: Ed. da USP, 1983.

CELLARD, André. Análise documental. In: POUPART, J.; DESLAURIERS, J.; GROULX, L.; LAPERRIÈRE, A.; MAYER, R.; PIRES, A. O. (orgs). A pesquisa qualitativa: Enfoques epistemológicos e metodológicos. 3. ed. Petrópolis: Vozes, 2012. p. 295-316.

COELHO, Marco Antônio; FALCÃO, Aluísio. Antônio Nóbrega: um artista multidisciplinar. Estudos Avançados, n.9, v. 23, p.59-70, jan./abr. 1995.

ENCONTRO PAN-AMERICANO DE JOGOS E ESPORTES AUTÓCTONES E TRADICIONAIS, 3, 2015. Ata da reunião entre museus de jogos e brinquedos. Palmas: Tocantins, 2015.

FUNARI, Pedro Paulo; CARVALHO, Aline Vieira de. O patrimônio em uma perspectiva crítica: o caso do Quilombo dos Palmares. Diálogos, v.9, n.1, p.33-47. 2005. Disponível em: http:// periodicos.uem.br/ojs/index.php/Dialogos/article/view/41416/21732 Acesso em: 20 out. 2018.

GOMES-DA-SILVA, Pierre Normando. Educação Física pela pedagogia da corporeidade: um convite ao brincar. Curitiba: CRV, 2016. v.14.

GUEDES, Angela Cardoso. Brinquedos: a formação da coleção do Museu Histórico Nacional. Anais do Museu Histórico Nacional, v.34, p.343-370, 2002. Disponível em: http://docvirt.com/ docreader.net/DocReader.aspx?bib=mhn\&pagfis=17649. Acesso em: 10 out. 2018.

GUEDES, Angela Cardoso. Brinquedos: por uma política de aquisição. Anais do Museu

Histórico Nacional. Rio de Janeiro, v.36, p.25-40, 2004 Disponível em: http://docvirt.com/ docreader.net/docreader.aspx?bib=MHN\&pasta=\&pesq=Brinquedos:\%20por\%20uma\%20politica\%20 de\%20aquisicao Acesso em: 10 out. 2018.

GUEDES, Ângela Cardoso. Empatia imediata, elo entre gerações: coleções de brinquedos no museu. In: BITTENCOURT, José Neves; BENCHETRIT, Sarah Fassa; TOSTES, Vera Lúcia Bottrel (ed.) História representada: o dilema dos museus. Rio de Janeiro: Museu Histórico Nacional, 2003. p. 135-142. Disponível em: http://docvirt.com/docreader.net/DocReader. aspx?bib=mhn\&pagfis=21957. Acesso em: 20 out. 2018.

INSTITUTO BRASILEIRO DE MUSEUS (IBRAM). Disponível em: http://www.museus.gov.br/osmuseus/museus-do-brasil/ Acesso em: 10 set.2018.

INSTITUTO BRASILEIRO DE MUSEUS (IBRAM). Guia de Museus Brasileiros, 2011. Disponível em: http://www.museus.gov.br/guia-dos-museus-brasileiros/ Acesso em: 20 out. 2018.

LABATE, Beatriz C.; GOLDSTEIN, Ilana. Ayahuasca. From Dangerous Drug to National Heritage: An Interview with Antonio A. Arantes. International Journal of Transpersonal Studies, v. 28, p.53-64, 2009. Disponível em: https://www.bialabate.net/texts/ayahuasca-comopatrimonio-imaterial-da-cultura-brasileira Acesso em: 10 set. 2018.

MARIN, Elizara Carolina. Jogo Tradicional: patrimônio material e imaterial. In: CONGRESO ARGENTINO, 12., y LATINOAMERICANO DE EDUCACIÓN FÍSICA Y CIENCIAS, 7. [Anais...]. 2017. Disponível em: http://congresoeducacionfisica.fahce.unlp.edu.ar/120-congreso/actas-2017/ Mesa\%2013 Marin.pdf Acesso em: 20 out. 2018. 
MARIN, Elizara Carolina; RIBAS, João Francisco Magno (orgs.). Jogo Tradicional e Cultura. Santa Maria: Ed. da UFSM, 2013.

MINAYO, Maria Cecília de Souza. O desafio da pesquisa social. In: MINAYO, Maria Cecília de Souza (org.); DESLANDES, Suely Ferreira; GOMES, Romeu. Pesquisa Social: Teoria, método e criatividade. Petrópolis, RJ. Vozes, 2009. p. 9-29

MOREIRA, Andressa Urtiga. "Brincante é um estado de graça": sentidos do brincar na cultura popular. 2015. 189 f. Dissertação. (Mestrado em Processos de Desenvolvimento e Saúde) Universidade de Brasília Instituto de Psicologia. Brasília, 2015.

MUSEU HISTÓRICO NACIONAL. Disponível em: http://mhn.museus.gov.br/index.php/o-museu/ Acesso em: 10 set. 2018.

OLIVEIRA, Marcus Vinícius Farias. Museu do Brinquedo Popular: espaços de saberes e de aprendizagens brincantes. In: MARIN, Elizara Carolina; GOMES-DA-SILVA, Pierre Normando, (org.) Jogos Tradicionais e educação física escolar: experiências concretas e sedutoras. Curitiba: CRV, 2016a. v.16.

OLIVEIRA, Marcus Vinícius Farias, et al. Brinquedos e brincadeiras populares: identidade e memória. Natal: Editora IFRN, 2010.

PADIGLIONE, Vincenzo. Museus etnográfico interpretativos, colecionadores e patrimônio. Entrevista concedida a Simone Lira da Silva e Rafael de Oliveira Rodrigues. Cadernos NAUI, v. 2, n. 2, p.1-10, jan./jun. 2013. Disponível em: http://naui.ufsc.br/files/2013/08/Entrevista-como-professor-Vincenzo-Padiglione-museus-etnogr\%C3\%A1ficos-interpretativos-colecionadores-epatrim\%C3\%B4nio.pdf Acesso em: 20 out. 2018.

PADIGLIONE, Vincenzo. Poetiche dal museo etnográfico: spezie morali e Kit di sopravvivenza. Imola: La Mandragora, 2010.

PELEGRINI, Sandra C., FUNARI, Pedro Paulo. 0 que é patrimônio cultural imaterial. São Paulo: Brasiliense, 2013.

ROGÉRIO, Yone Maria Andrade Paiva. O brinquedo no museu: um estudo na perspectiva da teoria ator-rede. 2013. 172f. Dissertação (Mestrado em Psicologia) - Universidade Federal de São João del-Rei, 2013.

SANTIAGO, Mariani Guedes. Museu de Brinquedos: lugar de memórias, culturas e encantamentos. 2017. 62f. Dissertação (Mestrado em Educação Física) - Universidade Federal de Santa Maria, 2017.

SAURA, Soraia Chung. O imaginário do lazer e do lúdico anunciado em práticas espontâneas do corpo brincante. Revista Brasileira de Educação Física e Esporte. v. 28, n.1, p.163-175, jan./mar. 2014.

SOUZA, Edison Roberto de. Do corpo produtivo ao corpo brincante: o jogo e suas inserções no desenvolvimento da criança. 2001. 226 f. Tese (Doutorado em Engenharia de Produção) Universidade Federal de Santa Catarina, 2001. 


\section{Apoio:}

O presente trabalho foi realizado com apoio da Coordenação de Aperfeiçoamento de Pessoal de Nível Superior - Brasil (CAPES) - Código de Financiamento 001. This study was financed in part by the Coordenação de Aperfeiçoamento de Pessoal de Nível Superior - Brasil (CAPES) Finance Code 001 